\title{
The Use of Ionizing Irradiation to Prepare Adhesives Based on Rosin and Ethylene Vinyl Acetate Copolymer
}

\author{
H. H. El-Nahas\#, Y. H. Gad, M. A. El-hady, A. B. \\ Ramadan* and M. M. Elsabah** \\ Radiation Research of Polymer Dept., National Centre for \\ Radiation Research and Technology (NCRRT), P. O. Box 29, \\ Nasr City, Egypt, "Radiation Control Dept., Nuclear \& Radiological \\ Regulatory Authority (NRRA), *Chemistry Dept., Faculty of Science, \\ Al Azhar University. "E mail: elnahashm@hotmail.com.
}

\begin{abstract}
DHESIVES based on rosin, ethylene vinyl acetate Acopolymer (EVA) blend and polyethylene-wax (PE-wax) by using ionizing irradiation were prepared. Low density polyethylene-wax (LPDE-wax) was added to aromatic hydrocarbon rosin/ EVA blend in the molten state and the miscibility and adhesion properties of ternary blends as hot-melt adhesive were investigated. Factors affecting the preparation process such as concentration and mixing percentage of polyethylene wax on improving the mechanical, thermal and adhesion properties of the prepared adhesive were studied. Also, the prepared adhesive has been tested through a series of standard rules of measurements for instance; peel strength, surface hardness, tensile-strength, elongation at break, thermal melting and scanning electron microscopy. The results showed that the increase of PE-wax added to the rosin/ EVA blend resulted in an increase in peel strength. The possibility of applications of the prepared adhesive in the field of automotive as adhesives for rubber to steel and rubber to rubber materials was suggested and applied.

Keywords: Adhesives, rosin, $\gamma$-rays.
\end{abstract}

Rosin from any of these three sources; Gum rosin, Wood rosin and Tall oil rosin is a mixture of organic acids called rosin acids. Minor components consist of rosin esters and anhydrides, unsaponifiable matter, and fatty acids. The rosin acids can be divided into two different types. These are the abietic acid type and the pimaric acid type, and unmodified rosin consists primarily of abietic type acids (Wang, 2008). 
Rosin by itself is generally unsuited for use in modern adhesive systems because it is subject to oxidation and other reactions as well as crystallization Because of this, most rosins for adhesive use have been subjected to one or more of a series of reactions to form modified rosins or rosin derivatives. The rosin-based polyamide was synthesized and studied as epoxy curing agent in the paper where, the results indicated that the rosin-derived polyamide could be used as an important alternative feedstock to petroleum-based analogs for the synthesis of epoxy with higher thermal stability (Zhen, 2013).

Blends of rosin and beeswax were studied in terms of their thermal and mechanical behaviours. It was shown that at room temperature, these blends exhibited a viscous behaviour in both the elastic and plastic regimes. From these measurements, a super-plastic behaviour was highlighted for blends with more than $60 \mathrm{wt} \%$ rosin. This super-plastic behaviour constitutes a real new potential in the mechanical reliability of adhesives based on rosin, which are more generally known for their very brittle behaviour. As a result, it should open the way for the design of new shapes (Gaillard, 2013).

Rosin acids are similar to many aromatic components in molecular rigidity because of the large hydrogenated phenanthrene ring structure, the carboxy group and conjugated double bond in rosin molecular with high activity sin can be easy to isomerzation such as addition, disproportionation, aminolysis, esterification, salt formation, decarboxylation reaction. Therefore, rosin and its derivatives can be modified to prepare as series of polymer and materials and additives (Atta et al., 2005 and Pingxu et al., 2012).

The aim of this work is to study the use of LDPE-wax prepared by using gamma irradiation and thermolysis techniques for use as modifying agent to rosin / EVA blend in the application of automotive industries as adhesive to adhere rubber to rubber and rubber to steel.

\section{Materials and method}

The LDPE pellets type, Melt Flow Index (MFI) $7 \mathrm{~g} / 10 \mathrm{~min}$ at $190^{\circ} \mathrm{C} /$ 2.16kg-Density $0.925 \mathrm{~g} / \mathrm{cm}^{3}$-Melting temperature $120^{\circ} \mathrm{C}$ was supplied by Exxon Mobil Co., Saudi Arabia. Rosin from HAB. Co, India.

Egypt. J. Rad. Sci. Applic., Vol. 27, No. 1-2 (2014) 
Basic structure and properties of rosin<smiles>CC(C)C1=CC2=CC[C@H]3[C@](C)(C(=O)O)CCC[C@]3(C)[C@H]2CC1</smiles>

Fig. 1. The basic structure of rosin; Abietic acid

Table 1: Properties of rosin

\begin{tabular}{|l|l|}
\hline Systematic name & $\begin{array}{l}(1 \mathrm{R}, 4 \mathrm{aR}, 4 \mathrm{bR}, 10 \mathrm{aR})-7 \text {-isopropy1-1,4a-dimethyl- } \\
1,2,3,4 \mathrm{a}, 4 \mathrm{~b}, 5,6,10,10 \mathrm{a}-\mathrm{dec} \text { - }\end{array}$ \\
\hline Molecular formula & $\mathrm{C}_{19} \mathrm{H}_{29} \mathrm{COOH}$ \\
\hline Appearance & Yellow resinous powder, crystals or chunks \\
\hline Solubility in water & Insoluble \\
\hline Melting point & $173^{\circ} \mathrm{C}(446 \mathrm{~K})$ \\
\hline Boiling point & $250^{\circ} \mathrm{C}(523 \mathrm{~K})$ at $9 \mathrm{mmHg}$ \\
\hline
\end{tabular}

EVA copolymer- $18 \%$ aromatic compound, MFI $135 \mathrm{~g} / 10 \mathrm{~min}$, melting point $67^{\circ} \mathrm{C}$ was obtained from Arkema Inc, USA.

White spirit from Misr Oil Co., Egypt.

\section{Preparation of PE wax}

Low density poly ethylene was irradiated through gamma irradiation at $50 \mathrm{kGy}$ in absence of air and then was heated at $350^{\circ} \mathrm{C}$ in a thermolysis process to obtain a low molecular wt type of low density polyethylene wax having a thermal melting of $110^{\circ} \mathrm{C}$ (El-Hady, 2008, El-Nahas, 2008 and Jixing, 2003)

$\gamma$-irradiation at $50 \mathrm{kGy}$ in absence of air

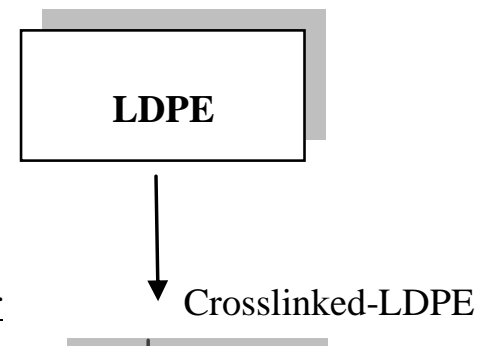

Thermolysis at $350^{\circ} \mathrm{C}$

\section{2\% Wax}

8\% Gases

Schem. 1. Diagram showing the preparation of PE-wax by using $\gamma$-rays.

Egypt. J. Rad. Sci. Applic., Vol. 27, No. 1-2 (2014) 


\section{Tensile strength and elongation at break}

The measurements of tensile strength $(\mathrm{Tb})$ and percentage of elongation at break (Eb) were carried out using an Istron Model 1195, UK, at a crosshead speed of $50 \mathrm{~mm} / \mathrm{min}$.

\section{Hardness test}

Surface hardness was measured by using ASTM D2240 specification, model $306 \mathrm{~L}$ type A, D durometer for soft and hard plastic.

\section{Peel adhesion tests}

The peel strength is defined as the load per unit width. Film samples were than cut into $2.5 \mathrm{cmx} 14 \mathrm{~cm} /$ strip. Peel strength was measured at $23^{\circ} \mathrm{C}$ by $180^{\circ} \mathrm{C}$ peel test using a tensile tester with a cross-head speed of $25.4 \mathrm{~m} / \mathrm{min}$ as described in the ASTM-D903 standard. The average force after the initial peak load was taken as the peel strength or according to the following equation:

$$
\mathrm{P}=\mathrm{W} . \mathrm{T}_{\mathrm{a}} \cdot \sigma
$$

Where, peel strength $(\mathrm{P})$, width of adhesive film sample $(\mathrm{W})$, adhesive film thickness $\left(\mathrm{T}_{\mathrm{a}}\right)$ and tensile strength $(\sigma)$. The test results were reported in grams per centimetre.

\section{Melting temperature}

Differential scanning calorimeter (DSC), A Shimadzu Type DSC-50 DSC system in nitrogen atmosphere at $20 \mathrm{ml} /$ min was sued in this study in the temperature range from ambient to $250^{\circ} \mathrm{C}$ at a heating rate of $10^{\circ} \mathrm{C} / \mathrm{min}$.

\section{Scanning electron microscope (SEM) analysis}

The surface morphology of different samples was studied by SEM. The SEM micrographs were taken with a JSM-5400 instrument by JEOL-Japan.

\section{Irradiation process}

Gamma irradiation was carried out using a cobalt-60 source of $\gamma$-rays manufactured by the Atomic Energy Authority of India, with a dose rate of $2.5 \mathrm{kGy} / \mathrm{h}$.

\section{Results and discussion \\ Preparation of rosin/EVA/PE-wax blend}

The samples were prepared through melt blending in a mechanical stirring provided with oil bath for heating.

Egypt. J. Rad. Sci. Applic., Vol. 27, No. 1-2 (2014) 
Rosin polymer was melted at $173^{\circ} \mathrm{C}$ and EVA was than added gradually with slow stirring rate at $60 \mathrm{rpm}$ for $10 \mathrm{~min}$ till a homogeneous fluid blend was appeared. PE wax was added after decreasing the temperature to $110^{\circ} \mathrm{C}$ with slow stirring rate at $60 \mathrm{rpm}$ for $15 \mathrm{~min}$ till a homogeneous viscous blend was appeared. The obtained blends were cast on glass plates and after cooling the samples were cut into strips with dimensions of $2 \times 8 \mathrm{~cm}$ in dimension and $0.3-1$ $\mathrm{mm}$ in thickness.

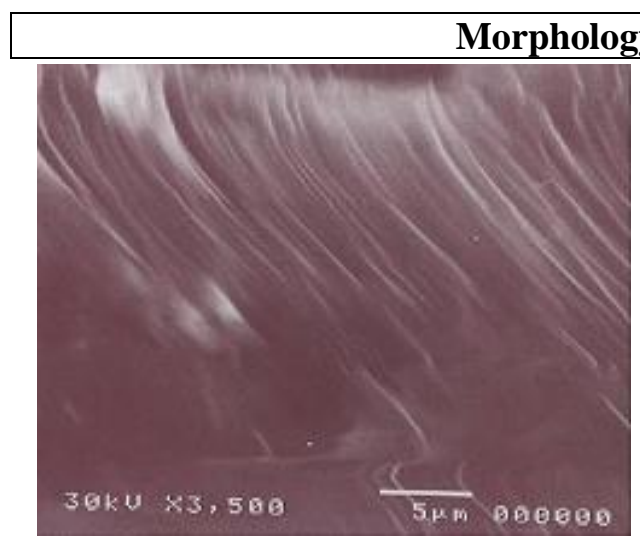

$\mathbf{A}$

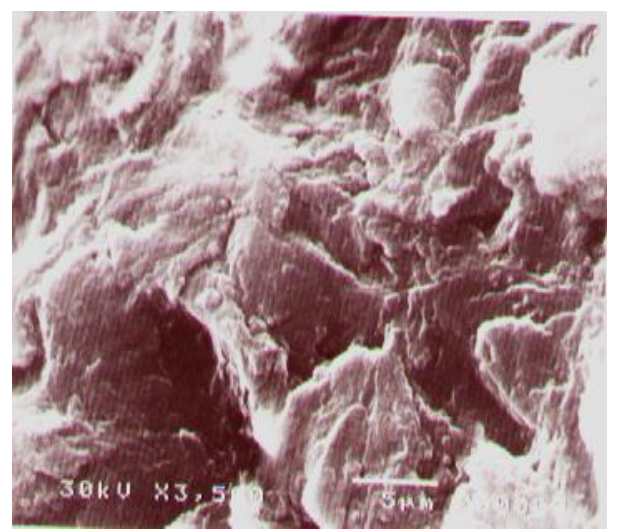

C

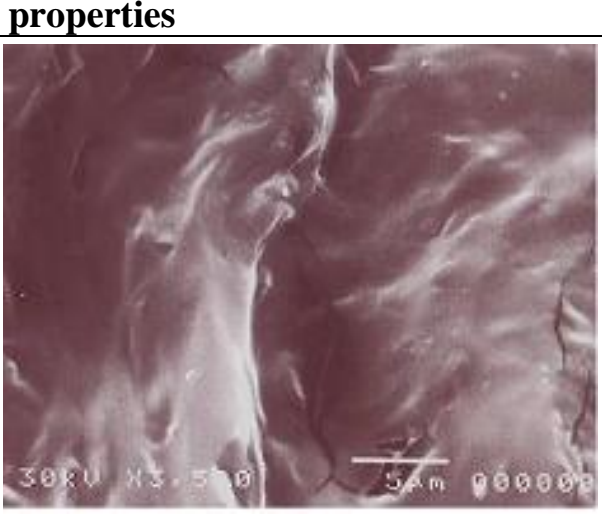

B

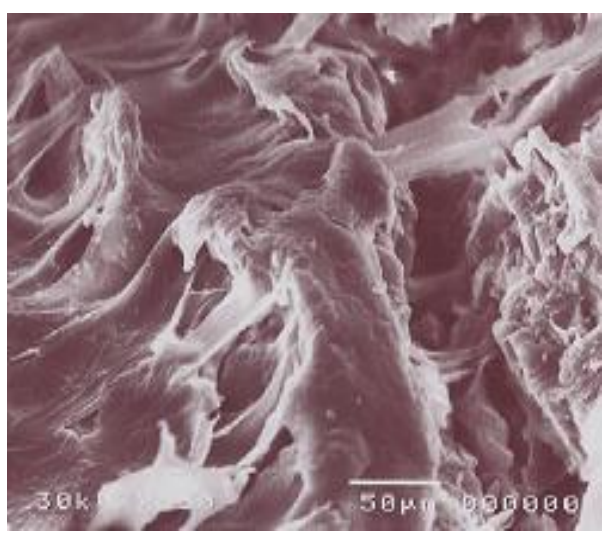

D

Fig 2. Micrographs of SEM for fractured surfaces from (a) EVA, (b) Rosin, (c) PE-wax blank and (d) EVA rosin blend PE-wax.

Micrograph (a) shows EVA as regular strains of smooth polymer and micrograph \& (b) shows rosin polymer as rock shape with solid and sharp edges but in micrograph. (c) PE-wax appears as irregular waves of wax bulks like shape \& (d) represents a full interaction between EVA, rosin and PE wax giving a dominant elastic muscle shape with strong and homogeneous sticky connection.

Egypt. J. Rad. Sci. Applic., Vol. 27, No. 1-2 (2014) 


\section{Thermal properties}

The miscibility of rosin/ EVA blend altered with addition of PE-wax. In addition, its thermal melting decreased with increasing wax concentration, where, the Tm of pure PE-wax is higher than pure EVA and less than pure rosin. Therefore, when the wax is added in rosin/ EVA blend system, the resulting ternary blend would need less energy to melt because of its decreased heat of fusion.

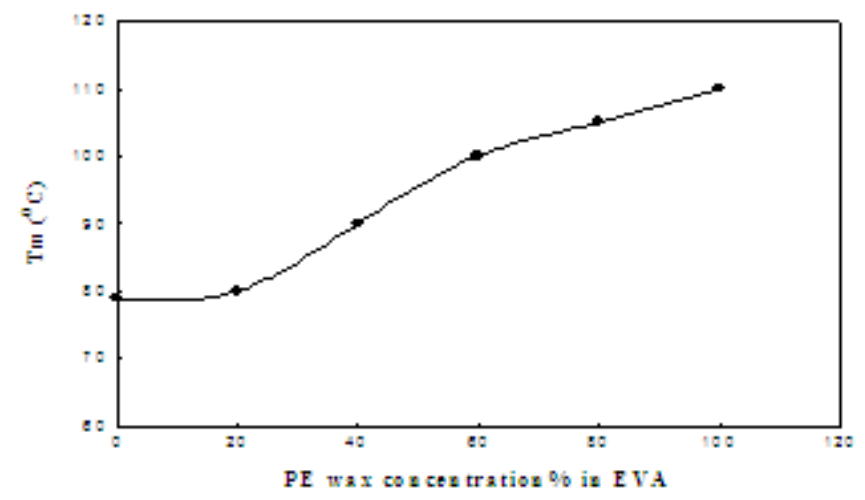

Fig. 3. Effect of PE-wax concentration\% in EVA on melting temperature.

Fig. 3. shows the effect of PE-wax concentration \% in EVA on thermal melting. The addition of PE-wax resulted in a slight increase in thermal melting (Tm) of EVA but was still below the thermal melting point of PE-wax itself.

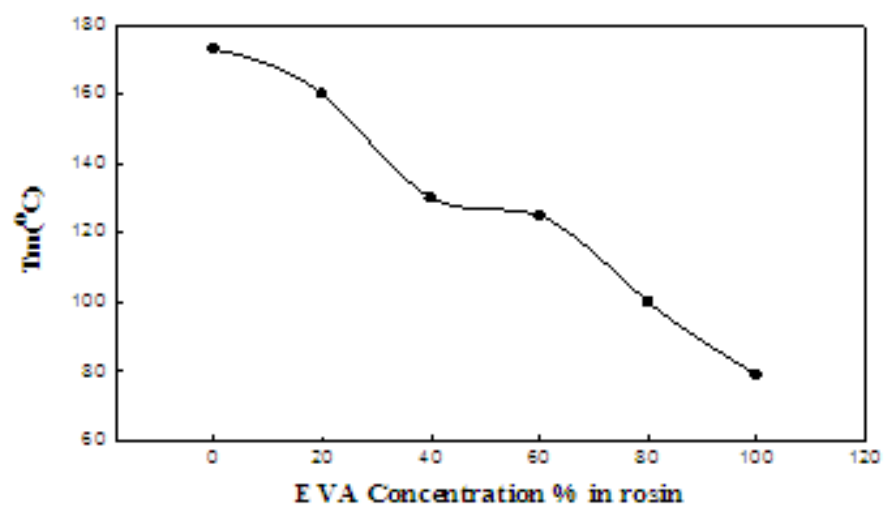

Fig. 4. Effect of EVA concentration\% in rosin on melting temperature.

Fig. 4. discusses the effect of blending EVA and rosin at different ratios on $\mathrm{T}_{\mathrm{m}}$ without adding PE-wax. It showed that EVA had the dominant effect to Egypt. J. Rad. Sci. Applic., Vol. 27, No. 1-2 (2014) 
decrease the $\mathrm{T}_{\mathrm{m}}$ of that blend. Also, the addition of PE-wax to this blend lead to in parallel to decrease the $\mathrm{T}_{\mathrm{m}}$ to reach almost to that $\mathrm{T}_{\mathrm{m}}$ of EVA at $60 \%$ of PEwax concentration as shown in Fig. 5. This is due to that PE-wax acted as a softening agent that led to enhancing the plasticization of rosin hardness causing in sequence to possess elasticity behaviour to the hard rosin. Also, at temperatures below the inflection temperature the solid-like behaviour of the blend was dominant over the liquid-like behaviour, but in the higher temperature region, liquid-like behaviour was dominant.

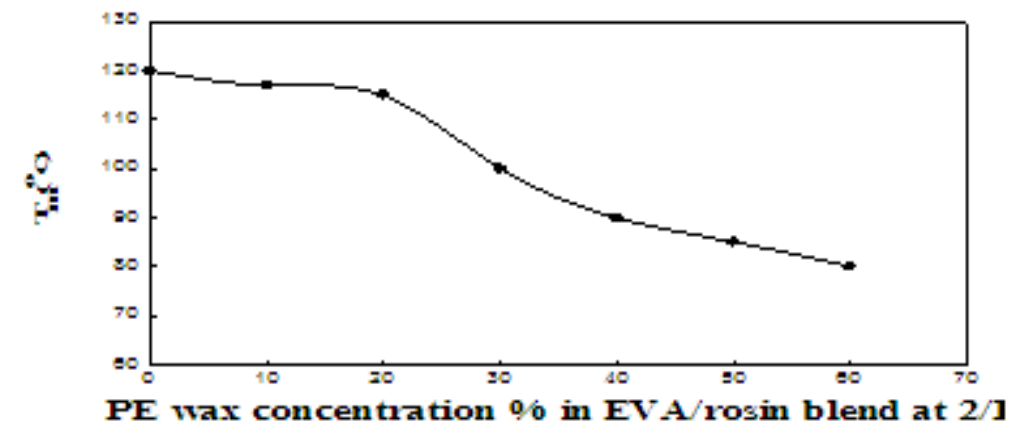

Fig. 5. Effect of PE-wax concentration \% in EVA/ rosin blend at 2:1 ratio on melting temperature.

\section{Mechanical properties}

Fig. $6 \& 7$ show the effect of PE-wax in rosin EVA blend to enhance the mechanical properties (tensile and elongation) where, the more elasticity was observed that caused a more tensile and elongation ratio than that blend without wax which was seemed as solid in shape and characters. This elasticity was also affected in the opposite way on surface hardness that lead to a slight decrease where, an obvious softening was occurred due to the addition of PE-wax to the rosin content in the blend to be as the same softness behaviour of EVA that caused to obtain a rubber like material in the blend properties as shown in Fig. 8.

Application of rosin /EVA/ PE-wax blends (Rubber to steel adhesive at hot melt process). Peel strength test was applied to determine the ability of PE- wax to enhance the adhesion strength of rosin / EVA blend at hot melt process, where, the adhesion strength of the ternary blend increased with increasing wax concentration. These results suggested that the ternary blend of rosin / EVA / PE-wax was homogeneous. 


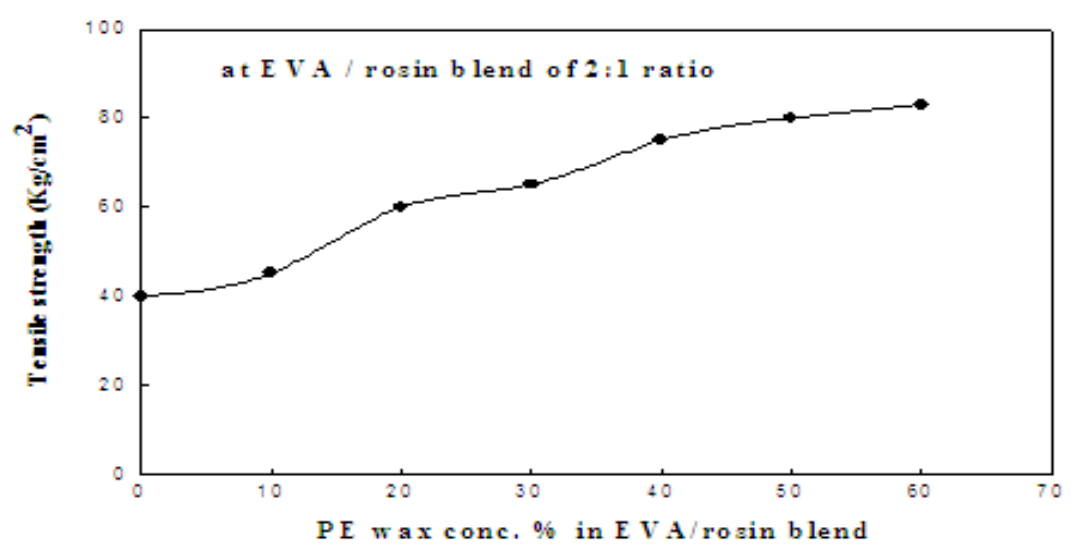

Fig. 6. Effect of PE-wax concentration \% in EVA/ rosin blend on tensile strength.

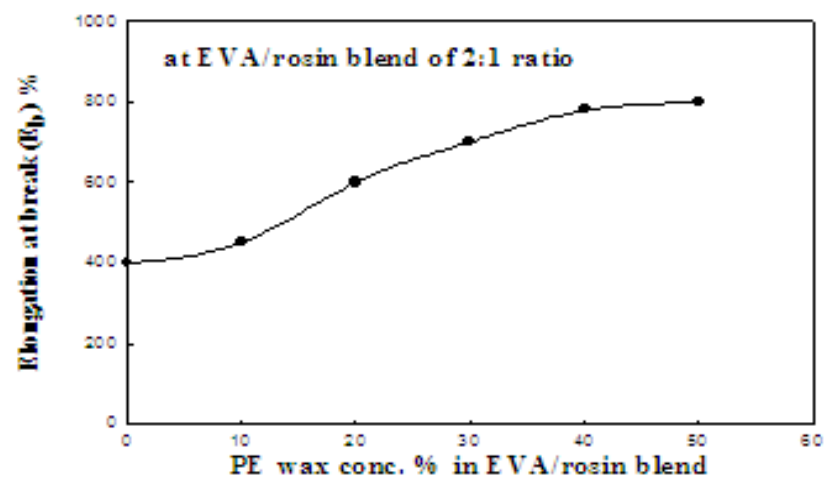

Fig. 7. Effect of PE-wax concentration $\%$ in EVA/ rosin blend on elongation at break.

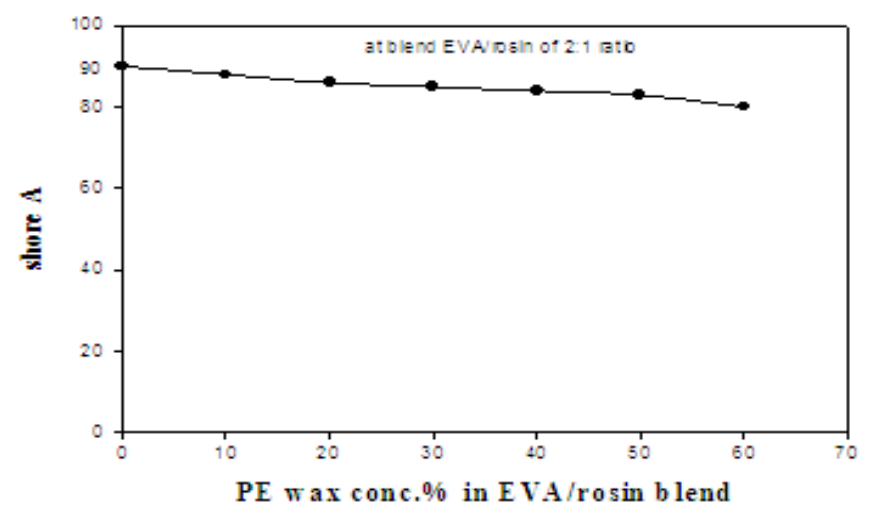

Fig. 8. Effect of PE-wax concentration \% in EVA/ rosin blend on surface hardiness.

Egypt. J. Rad. Sci. Applic., Vol. 27, No. 1-2 (2014) 
Fig. 9. observes the effect of PE-wax \% in rosin/ EVA blend on the peel strength of butyl rubber (cautshouk mould) as a material to iron steel as a substrate. The figure showed that the increase of PE-wax added to the blend resulted in an increase in peel strength till to $2500 \mathrm{~g} / \mathrm{cm}$ width that gave a cut off point at the ratio of 75\% PE-wax added to the rosin / EVA blend.

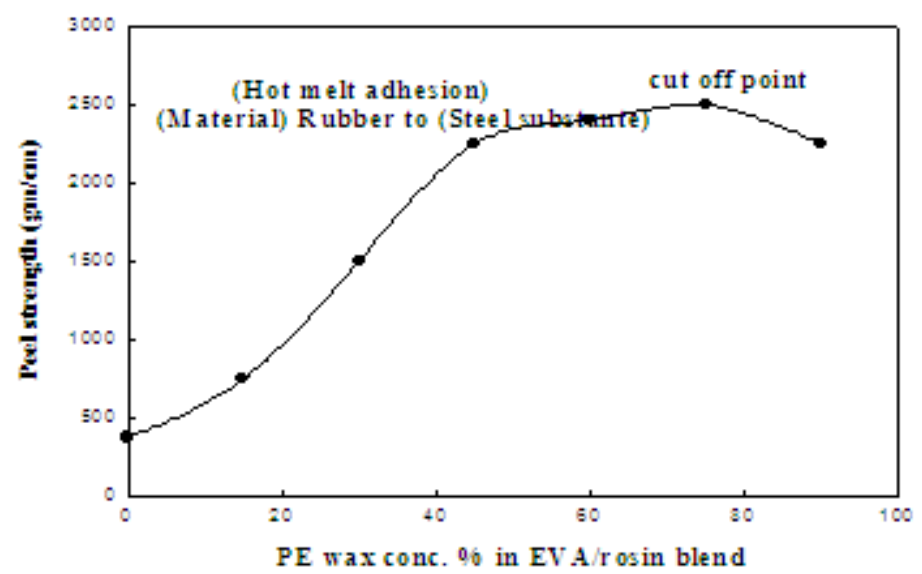

Fig. 9. Effect of PE-wax concentration \% in EVA/ rosin blends on adhesion peel strength of rubber to steel.
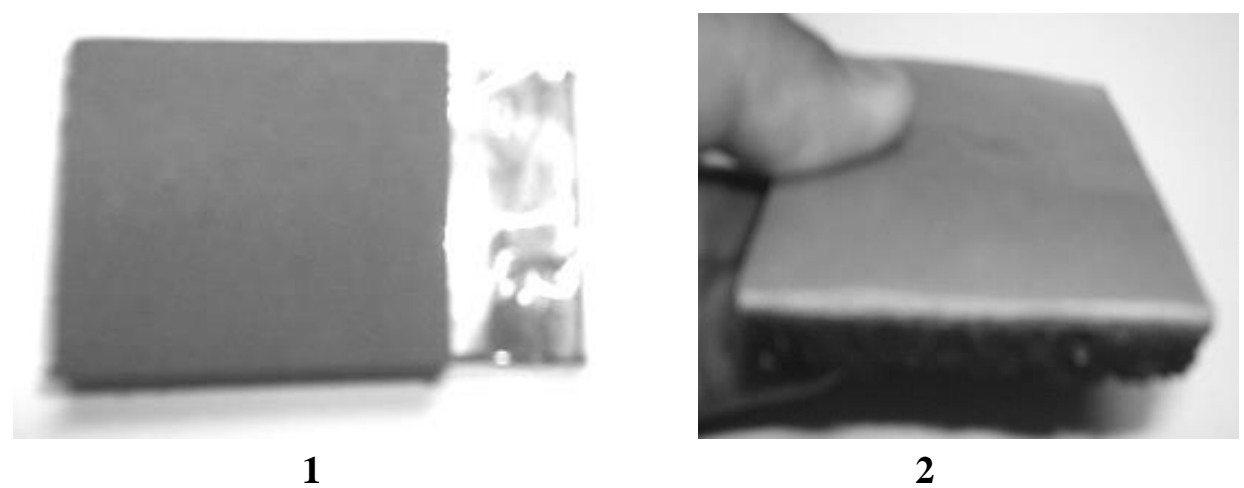

2

Photographic view: (1) Rubber to steel adhesion. (2) Rubber to rubber adhesion.

The prepared blend of rosin/EVA/PE-wax offers three types of polymer behaviours to possess specific and modified adhesive where, rosin as tackifier to increase the tack and the stickiness of the surface of the adhesive, EVA as stripping polymer with its rubber behaviour to increase mechanical strength and film formation of the adhesive and PE-wax as a softening agent to break down 
the rosin hardness to be levelled and elastic as EVA, also PE-wax has possessed a sticky behaviour for whole the blend to be applied as a hot melt adhesive to adhere rubber to steel or rubber to rubber as shown in photographic view $1 \& 2$.

\section{Conclusion}

The results showed that blending of rosin and EVA at different ratios on $\mathrm{T}_{\mathrm{m}}$ without adding PE-wax had the dominant effect to decrease the $\mathrm{T}_{\mathrm{m}}$ of that blend. Also, the addition of PE-wax to this blend lead to in parallel to decrease the $\mathrm{T}_{\mathrm{m}}$ to reach almost to $\mathrm{T}_{\mathrm{m}}$ of EVA at $60 \%$ of PE-wax concentration. The effect of PE-wax in rosin / EVA blend showed a more elasticity that caused a more tensile and elongation ratio than that blend without wax which was seemed as solid in shape and characters. This elasticity was also affected in the opposite way on surface hardness that leads to a slight decrease. The results showed that the increase of PE-wax added to the blend resulted in an increase in peel strength till to $2500 \mathrm{~g} / \mathrm{cm}$ width that gave a cut off point at the ratio of $75 \%$ PE-wax added to the rosin /EVA blend.

The study offers a specific adhesive for adhering rubber to rubber and rubber to steel which could be applied in the field of automotive.

\section{Acknowledgement}

The authors gratefully acknowledge MOBIAN Company, Alexandria, Egypt for help in measurements and applications.

\section{References}

Atta, A. M., Mansour, R., Abdou, M. I. and Sayed, A. M. (2005) Synthesis and characterization of tetra-functional epoxy resins from rosin. Egypt. J. Polym. Res., 12, 127.

El-Hady, M. A. (2008) The using of radiation to prepare PE- and PP-waxes for using in some polymer emulsion and blend applications. Ph.D.Thesis, Chemistry Dept., Al Azhar University, Egypt. pp 133-149.

El-Nahas, H. H., Ramadan, A. B., El-Hady, A. A. and Hassan, E. A. (2008) Thermolysis process of gamma irradiated LDPE and PP to produce waxes for possible use in lubricant and pencils industries. Egypt. J. Rad . Sci. Applic., 21, 40.

Gaillard, M., Girard, G., Monge, A., Burr, E., Darque Ceretti, E. and Felder, R. (2013) Superplastic behavior of rosin/beewax blends at room temperature. $J$. App. polym. Sci., 128, 2713.

Egypt. J. Rad. Sci. Applic., Vol. 27, No. 1-2 (2014) 
Shuyuan, J. L., Xuan, W. and Xiangyang, L. (2003) Study on the conversion technology of wast polyethylene plastic to polyethylene wax. China Energy Sourc., 25, 27.

Zhen, M., Xiao, N., Yi, W., Lin, C. and Fu, G. (2013) Rosin-derived polymide as epoxy curing agent. China. J. Forest product \& Industries, $2,5$.

Chen, P., Zeng, X., Li, H., Liu, X., Lia, D., Li, X. (2012) Preparation and characterization of polyacrylate/polymerized rosin composite emulsion by seeded semicontinuous emulsion polymerization. China. J. App. Polym. Sci., 124, 4694.

Wang, H. H., Liu, B. Liu, X. Q., Zhong, J. W. and Xian, M. (2008) Synthesis of biobased epoxy and curing agents using rosin and the study of cure reactions. China. Green Chem., 10, 1190.

(Received: 17/12/2013;

accepted: 09/02/2014) 


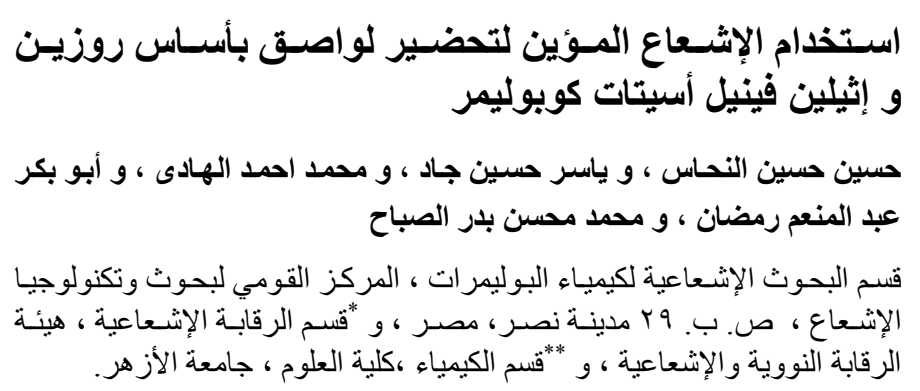

تهدف الدراسـة الي تحضير لو اصفق بأسـاس روزين و إيثليلين فينيل

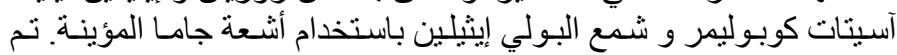

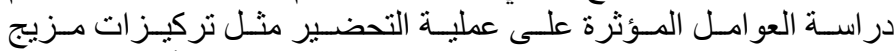

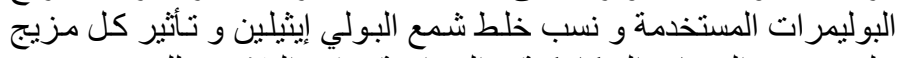

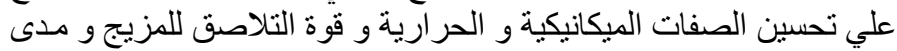

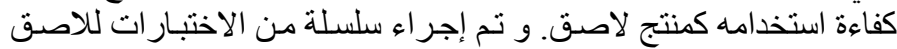

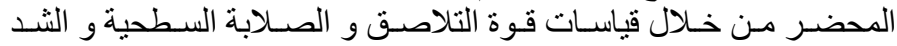

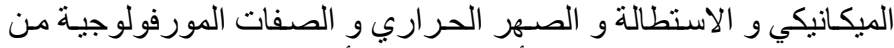

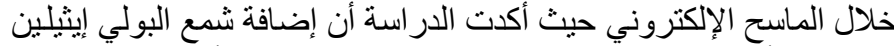

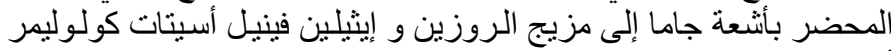

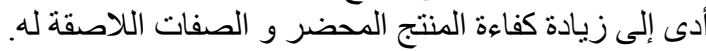

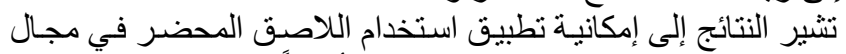

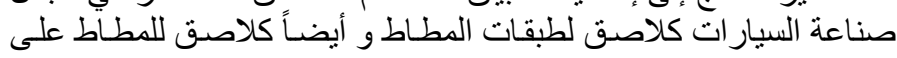

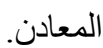

Egypt. J. Rad. Sci. Applic., Vol. 27, No. 1-2 (2014) 